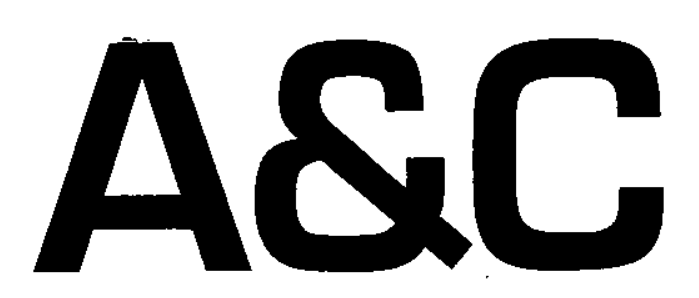

Revista de Direito Administrativo \& Constitucional

Belo Horizonte

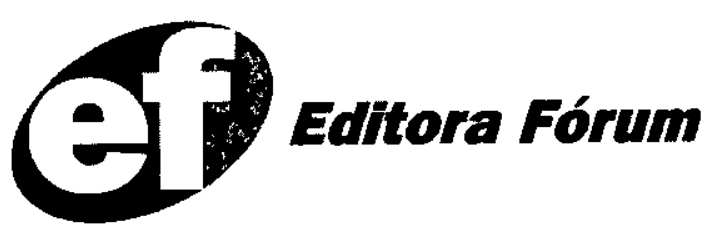

\author{
Curitiba
}

IPDA

Instituto Paranaense de Direito Administrativo 
A246 A\&C REVISTA DE DIREITO ADMINISTRATIVO E CONSTITUCIONAL

Ano 3, n. 11 jan./ mar. 2003)

Belo Horizonte : Editora Fórum, 2003

$17 \times 24 \mathrm{~cm}$

Trimestral

ISSN: $1516-3210$

ano 1, n.1, 1999 até ano 2, n.10, 2002

publicada pela Editora Juruá em Curitiba

1. Direito Administrativo

2. Direito Constitucional

I. Ed. Fórum.

CDD: 342

CDU: 342.951
(C) Editora Fórum Ltda, 2003

Proibida a reprodução total ou parcial desta obra, por qualquer meio eletrônico, inclusive por processos xerográficos, sem autorização expressa do editor.

Editora Fórum

Av. Afonso Pena, $2770-15 \% 16^{\circ}$ andar Funcionários CEP 30130-007 - Belo Horizonte - MG

Tel.: 08007043737

e-mail: ediforum@ediforum.com.br www.ediforum.com.br

Editor responsável:

Luís Cláudio Rodrigues Ferreira

Projeto.gráfico e Diagramaçăo:

Rogério de Souza Magalhāes Júnior

Revisão:

Equipe Fórum

Bibliotecária:

Nilcéia Lage de Medeiros

Dados Internacionais de Catalogação na Publicação (CIP)

(Câmara Brasileira do Livro, SP, Brasil) 


\title{
Reserva de Vagas nas Universidades Públicas para Alunos Egressos da Rede Pública de Ensino
}

\author{
Reinaldo Moreira Bruno \\ Mestre em Direito, Professor de Direito \\ Administrativo da UNIMES E UNIMONTE \\ e Membro do Instituto Brasileiro de Direito \\ Administrativo
}

\section{Introdução}

Projeto de lei submetido ao Congresso Nacional em 1999 deu causa conflito de opiniões entre parlamentares, ministros e a própria imprensa quanto à constitucionalidade ou não da matéria que determina reserva de $50 \%$ (cinqüenta por cento) de vagas em instituições públicas de ensino superior a alunos egressos das escolas da rede pública, desde que tenham realizado todo o curso médio nestas.

Reitores de universidades públicas entraram na discussão, alegando a inconstitucionalidade e discriminação, a possibilidade da queda da qualidade, o aumento na retenção de alunos nos cursos e outros problemas correlatos ou deles decorrentes.

A grande imprensa, através dos dois maiores jornais de São Paulo, em editoriais manifestaram-se em idêntico sentido, com títulos extremamente semelhantes, senão vejamos: em 5 de setembro de 1999, a Folha de S. Paulo manifestou-se: "Escola Pública e Demagogia"; o concorrente, O Estado de São Paulo, após dois dias: "Vestibular e Demagogia". Em ambos são disparadas críticas, afirmando que, na verdade, o objetivo é puramente e tão-somente aumentar a discriminação, em vez de combaterem a "má-qualidade" reconhecida por ambos do ensino público, transferindo para o "terceiro grau" alunos mal preparados e que por certo não concluirão o curso.

O Ministro da Educação critica o projeto afirmando: "A democratização do acesso ao ensino superior passa pela melhoria da escola pública", terminando por acusar o projeto de paliativo dentro da estrutura elitista e excludente do ensino brasileiro.

O presidente do Conselho Nacional de Educação, Éfrem Maranhão, na mesma matéria, afirma: "A universidade é uma casa de meritocracia"2, onde os critérios de seleção devem levar em conta o mérito do candidato, desde que garantida a igualdade de condições. 
Terminando o contorno do quadro, o Ministro da Educação Paulo Renato, em artigo entitulado "O novo Ensino Médio brasileiro"3, vem propondo alterações profundas no Ensino Médio, acusando-o de burocrático, ineficiente, sem qualquer tipo de utilização que não o de preparar o aluno para o vestibular, entre outras justificativas para a mudança proposta.

Cerca de $45 \%$ (quarenta e cinco por cento) das vagas nas universidades públicas são ocupadas por alunos oriundos da rede pública, e o restante, pelos estudantes das escolas particulares. Assim posto não há grande significado, porém, ao verificar-se que $89,7 \%$ das vagas do curso de Medicina da Universidade de São Paulo são preenchidas por alunos da rede particular; que no curso de Direito da Universidade Federal do Mato Grosso 92, $1 \%$ dos alunos são oriundos das escolas particulares, é de se concluir que os alunos da rede pública têm acesso à universidade pública somente nos cursos que não têm grande interesse para os estudantes oriundos da rede particular de Ensino Médio .

$\mathrm{Na}$ verdade, desloca-se o eixo da questão para a isonomia, para se evitar a discriminação, porém há um aspecto tão relevante quanto este não abordado $\mathrm{e}$ que merece uma análise, por mais rápida que seja: a qualidade do serviço público prestado pelo Estado como fator de discriminação dos alunos egressos do ensino público.

\section{Educação como serviço público}

A Carta de 88, em seu art. 175, caput, estabelece: "Incumbe ao Poder Público, na forma da lei, diretamente ou sob regime de concessão ou permissão, sempre através de licitação, a prestação de serviços públicos."

Em um sentido amplo; todas as atividades que o Estado desempenha constituem serviços públicos, com alguns administrativistas entendendo ser esta a única ou a primordial atividade do Estado, destacando-se entre eles Gaston Géze e Léon Duguit.

No Brasil, Hely Lopes Meirelles faz eco a Duguit afirmando: "é a atribuição primordial da Administração Pública, não se justificando sua presença senão para prestar serviços à comunidade"4 .

Diogo de Figueiredo Moreira Neto conceitua os serviços públicos: "uma atividade da Administração que tem por fim assegurar, de modo permanente, contínuo e geral, a satisfação de necessidades essenciais ou secundárias da 
sociedade, assim por lei consideradas, e sob as condições impostas unilateralmente pela própria administração" .

- Por derradeiro, Celso Antonio Bandeira de Meio assim define:

serviço público é toda atividade de oferecimento de utilidade ou comodidade material fruível diretamente pelos administrados, prestados pelo Estado ou por quem lhe faz as vezes, sob um regime de direito Público - portanto - consagrador de prerrogativas de supremacia e de restrições especiais -instituídos pelo Estado em favor dos interesses que houver definido como próprios no sistema normativo ${ }^{6}$.

Diogo de Figueiredo Moreira Neto, tratando do tema serviços públicos, ensina:

O interesse público, a supremacia do coletivo sobre o individual, expresso no princípio geral da finalidade, informa os seguintes princípios específicos dos serviços públicos da continuidade, da generalidade, da modicidade do aperfeiçoamento. Esses princípios estão positivados nas regras do artigo $175 \mathrm{da}$ Constituição Federal ${ }^{7}$.

Continuando, trata individualmente dos princípios que regem esta atividade do Poder Público, passando pelos princípios da continuidade, da generalidade, da modicidade e chega ao aperfeiçoamento. No que tange a este último, textualmente afirma: "O poder-dever de agir exige dela esforço e vigilância constantes para manter a eficiência no grau máximo possível(...)."

Sem reproduzir o amplo tratamento legislativo oferecido ao tema educação em nossa Constituição, algumas de suas disposições aqui devem ser necessariamente ressaltadas.

$\mathrm{O}$ art. 206 estabelece princípios gerais que regem a atividade do ensino no país estabelecendo: "I - igualdade de condições para o acesso e permanência na escola; IV - gratuidade do ensino público em estabelecimentos oficiais; VI - gestão democrática do ensino público, na forma da lei; VI - garantia de padrão de qualidade".

Já no art. 214 constata-se, na Lei Fundamental, a necessidade de implantar o plano nacional de educação com objetivos bem definidos e assim elencados: "II - universalização do atendimento escola; III - melhoria da qualidade do ensino".

${ }^{5}$ MOREIRA NETO, Diogo de Figueiredo. Curso de direito administrativo, p. 323.

${ }^{6}$ MELLO, Celso Antonio Bandeira de. Curso de direito administrativo, p. 477.

${ }^{7}$ MOREIRA NETO, Diogo de Figueiredo. Curso de direito administrativo, p. 324.

${ }^{8}$ MOREIRA NETO, Diogo de Figueiredo. Curso de direito administrativo, p. 325. 
Norma jurídica, inclusive mandamento constitucional, deve necessariamente ser aplicada, regendo, pois, as relações sociais e condutas humanas, e ter enfim sua efetiva aplicação para a finalidade para a qual foi editada. $O$ operador do direito tem que ter em mente que mandamento constitucional não é a simples manifestação de intenções na busca do atendimento à qualidade de vida do cidadão.

Este pensamento encontra amparo na doutrina constitucionalista, em que, desde Rui Barbosa, existe a reafirmação da eficácia da norma constitucional:

Não há, numa Constituição, cláusulas a que se deve atribuir meramente o valor moral de conselhos, avisos ou lições. Todas têm força imperativa de regras, ditadas pela soberania nacional ou popular a seus órgãos. Muitas, porém, não se revestem dos meios de ação essenciais ao seu exercício, os direitos que outorgam, ou os encargos que impõem: estabelecem competências, atribuições, podres, cujo uso tem que aguardar que a Legislatura, segundo o seu critério, os habilite a se exercerem ${ }^{9}$.

Este é o quadro que se apresenta: por expressa e cogente determinação constitucional, a oferta de educação é atribuição do Poder Público, considerada como serviço público necessário e essencial, podendo ser prestada por particulares sob fiscalização e controle estatal, inescusável ao Poder Público, atendendo aos princípios já elencados como de garantia do padrão de qualidade, como de todo e qualquer serviço público.

\section{Incidência do princípio da eficiência}

Não obstante a exigência do padrão de qualidade do processo educacional; assim como em toda a atividade do poder público quando da oferta de utilidades e necessidades ao cidadão, por expresso dispositivo constitucional, a interpretação sistêmica de nossa Carta impõe ainda, a análise de outro dispositivo incidente em tal questão.Trata-se, pois, do recém-inserido princípio constitucional da eficiência, cogente e norteador de toda ação da Administração Pública, no caput do art. 37 da Constituição, como resultado da Emenda Constitucional $n^{\circ} 19$.

Considerada a época de promulgação da emenda mencionada, junho de 1998, a conceituação da eficiência do setor público deve ser realizada; eis que a própria doutrina, com expoentes dos mais renomados, acaba por evitar enfrentar sua conceituação sob o argumento de sua fluidez e dificuldade na conceituação. 
Celso Antonio Bandeira de Mello afirma:

Quanto ao princípio da eficiência, não há nada a dizer sobre ele. Trata-se, evidentemente, de algo mais do que desejável. Contudo, é juridicamente fluido e de tão difícil controle do lume do direito, que mais parece um simples adorno agregado ao artigo 37 ou o extravasamento de uma aspiração do que buliram no texto, ${ }^{10}$.

Hely Lopes Meirelles reconhece a relevância da inserção do princípio e, enfrentando, manifesta-se:

O princípio da eficiência exige que a atividade administrativa seja exercida com presteza perfeição e rendimento funcional. É o mais moderno princípio da função administrativa, que já não se contenta em ser desempenhada apenas com legalidade, exigindo resultados positivos para o serviço público e satisfatório atendimento das necessidades da comunidade e de seus membros ${ }^{11}$.

No dizer de Hely, a eficiência administrativa não abrange somente a produtividade do exercente do cargo ou da função, abrange também a perfeição do trabalho e sua adequação técnica aos fins visados pela Administração, com o fito de que se avaliem os resultados e busque-se o aperfeiçoamento do pessoal.

Em idêntico sentido labora Maria Sylvia Zanella Di Pietro e acentua a dupla ótica sob a qual deve ser observado o princípio da eficiência:

o modo de atuação do agente público e, a que efetivamente nos interessa qual seja, o modo de organizar, estruturar, disciplinar a Administração Pública, também, com o mesmo objetivo de alcançar os melhores resultados na prestação do serviço público ${ }^{12}$.

É de se concluir, ante expresso mandamento constitucional, que a atividade de oferecer o serviço de educação de forma irrenunciável é do Estado, devendo necessariamente estar submetida ao princípio da eficiência, assim como toda e qualquer atividade estatal, buscando permanentemente oferecer a melhor qualidade e, portanto, os melhores resultados.

O próprio Ministro de Estado da Educação, Paulo Renato de Costa Souza, elenca inúmeras necessidades e providências para alteração do Ensino Médio, na busca da qualidade tão desejada, encerrando: "É trabalho para no mínimo cinco anos, especialmente para os professores, verdadeiros protagonistas da reforma. Deles,

${ }_{10}$ MELLO, Celso Antonio Bandeira de. Curso de direito administrativo, p. 75.

${ }^{11}$ MEIRELLES, Hely Lopes. Direito administrativo brasileiro, p. 89.

${ }^{12}$ DI PIETRO, Maria Sylvia Zanella. Direito administrativo, p. 83 -84. 
principalmente, dependerá o sucesso do novo Ensino Médio que o Brasil quer e merece ofertar aos seus cidadãos ${ }^{13}$.

Não obstante a própria confirmação ministerial quanto aos problemas de qualidade do Ensino Médio, apesar de propostas para sua melhoria, há que se voltar as atenções para o problema do ensino básico, ou seja, do Ensino Fundamental, que vai desaguar no Ensino Médio, ambos da rede pública, causando inúmeros transtornos e ensejando gravíssimos problemas na eficiência.

O Ensino Fundamental, que por expresso mandamento constitucional é obrigatório e universalizado, vem enfrentando graves problemas na rede pública.

Nos termos da Lei de Diretrizes e Bases da Educação, quanto à possibilidade de adoção da chamada "progressão continuada" no Ensino Fundamental, em vez da "ultrapassada" evolução seriada, justificada na manutenção e elevação da auto estima do educando, ela vem trazendo conseqüências seríssimas ante a péssima instrumentalização para sua aplicação.

No Estado de São Paulo, por exemplo, através da Resolução SE 04, de 15/ 01/ 98, veio a ser implantada a progressão continuada, que acabou por transformar-se na chamada "aprovação automática", onde os educandos são promovidos em um processo de avaliação em ciclos de quatro anos, causando grandes problemas ao professor em decorrência da falta de instrumentalização adequada para sua efetiva utilização.

Também é de se salientar que, por detrás desta implantação de cima para baixo, sem a necessária preparação do profissional para o pleno exercício, duas questões ficam encobertas, mas de grande interesse das classes dominantes: a) sem retenção, a criança passa pela escola e ali permanece o mínimo legal, sem necessidade de investimentos adicionais, situação que ocorre quando há a possibilidade de retenção, tornando assim o aluno uma importância a ser despendida desnecessariamente pelo Estado; b) a manutenção do status quo de exclusão e discriminação das classes menos favorecidas da sociedade.

O quadro chega a tal ponto que é possível encontrar-se a seguinte frase: "NO DINA VIT DO DEABINU D DONI COME KICNA DO NO BA BASINU TERÃ MLAZSA ." (No dia 22 de abril, comemoramos os 500 anos do nosso Brasil, que é uma terra maravilhosa. $)^{14}$ A autoria é de um aluno de quarta série do Ensino Fundamental da rede pública de ensino de São Paulo, que constata-se analfabeto e, nesta sistemática de aprovação automática, será levado ao Ensino Médio e a seguir colocado à porta dos cursos superiores. 
O Ministro da Educação, Paulo Renato, assim manifesta-se: "É o fracasso da escola. Ela tem de fazer o aluno aprender. Temos que exigir dedicação dos professores." 15

Deparamo-nos, pois, com uma evidente e confessa ineficiência da escola pública, tanto no Ensino Fundamental como no Médio. É dever da sociedade exigir, como tomadora de serviços públicos de natureza educacional, prestados diretamente pelo Poder Público, a possibilidade de ingressar em universidade pública, no curso de sua preferência, e não naqueles cursos em que restam vagas a preencher, assegurando-se, assim, a isonomia entre o aluno egresso da escola particular e o aluno oriundo da escola pública.

$\mathrm{Na}$ hipótese de ineficiência do serviço prestado, a sociedade, através do Estado, deve suportar também tal ônus e contribuir para a reversão do sombrio quadro aqui delineado, sob pena de a ação estatal, esta sim, promover a efetiva discriminação dos alunos egressos da rede pública, no que tange ao acesso à Universidade Pública.

\section{0 princípio da isonomia condena a proposta?}

Alegam os críticos a inconstitucionalidade por impor forte discriminação e eventual prejuízo à qualidade do desenvolvimento da universidade pública, hoje centro de excelência do conhecimento brasileiro.

Às criticas de inconstitucionalidade, por ferir a isonomia, o autor da proposta responde vigorosamente, contra-atacando com o seguinte argumento: "Os que combatem o meu projeto não confessam, mas há um preconceito de classe."16

\subsection{O princípio da isonomia}

Desde sempre, dos filósofos aos juristas de nosso tempo, a igualdade está vinculada à justiça.

A justiça distributiva é vista como igualdade na distribuição das honras, riquezas e outros bens entre os cidadãos. "O injusto é desigual, e o justo é o igual", no dizer de Aristóteles.

A isonomia visa formalmente exigir o mesmo tratamento para pessoas iguais, sendo que a dificuldade está em decidir o que é igual, que aspectos são relevantes ou não, valiosos ou sem valor. 
Montesquieu, em sua obra $O$ Princípio das Leis, invocou a isonomia para manter os tribunais especiais de que dispunham os nobres, sob o argumento de que o menor dos cidadãos tem, em um Estado livre, o direito de ser julgado por seus pares, renunciando ao princípio da tripartição dos poderes.

A partir da Revolução Francesa, os democratas concebem a igualdade como rejeição a quaisquer privilégios e discriminações entre cidadãos, salientando-se, porém, que não se via discriminação na exclusão das mulheres dos cargos civis e militares, como prerrogativas de cidadão.

Em sentido concreto, a igualdade trás consigo inúmeras e profundas divergências, pois envolve posturas políticas, ideológicas e axiológicas; como ensina Canotilho, é fundamental partir da Constituição historicamente posta, a qual positiva as opções axiológicas e ideológicas fundamentais, objetivando e cristalizando valores em princípios jurídicos.

Toda idéia de igualdade (e de justiça), no Direito, supõe o confronto, a comparação, sendo que, pelo contraste no tratamento igual ou desigual, nascem os sentimentos de justiça ou de injustiça.

Nossa Carta, em seu artigo $5^{\circ}$, reza que todos são iguais perante a lei e, por unanimidade, o alcance deste princípio não se restringe em nivelar os cidadãos diante da norma legal posta, mas a própria lei não pode ser editada em desconformidade com a isonomia.

Tratando a igualdade, verifica-se:

A igualdade, que aparece como garantia constitucional tem conotação gongórica, notadamente quando se qualifica como sem distinção de qualquer natureza. Não se trata, como se poderia pensar a partir da referida expressão, de uma igualdade absoluta ou integral de todos os homens em todos o setores e bens da vida. Igualdade neste sentido, seria utópica, mesmo porque os seres humanos, já na origem, nascem diferentes ${ }^{17}$.

Tem-se que igualdade é sempre uma relação interpessoal, segundo a qual as pessoas iguais recebem porções iguais das coisas a serem partilhadas, enquanto aquelas desiguais hão de receber parcelas desiguais dessas mesmas coisas.

Para alguns estudiosos do tema, o Estado Social representa uma evolução do conceito de democracia na busca da igualdade socioeconômica pela redução das grandes diferenças materiais existentes entre os grupos e os indivíduos, integrando-se à ordem constitucional, sem qualquer contradição com a noção de democracia; ao contrário, é dela manifestação concreta. 
Os direitos fundamentais deixam de ser viștos como simples limitações à ação estatal, mas convertem-se em instrumentos efetivos que devem assegurar o pleno desenvolvimento da personalidade de cada indivíduo e sua dignidade, completando-se com direitos econômicos e sociais eficazes, exigíveis e não meramente programáticos.

O constitucionalismo moderno trabalha com exigências jurídicas concretas, abandonando a igualdade formal, e busca a igualdade na ordem dos fatos, de caráter econômico-material.

O Estado intervencionista põe-se a serviço de uma nova ordem social e econômica mais justa, menos desigual, em que seja possível a cada homem desenvolver digna e plenamente sua personalidade.

Compatibilizam-se o Estado de Direito e o Estado Social, com as Constituiçōes encontrando fórmulas adequadas, assegurando clássicas garantias jurídicas, com a busca de metas de maior justiça social e condições efetivas de uma vida digna para todos, por meio do desenvolvimento e da conciliação entre liberdade e solidariedade, isto na lição do festejado José Afonso da Silva, em seu curso de Direito Constitucional Positivo.

Também não há incompatibilidade entre o princípio da igualdade no Estado de Direito e o princípio da igualdade que visa à redução dos contrastes econômico-sociais, à redistribuição de renda, enfim; o princípio da igualdade serve ao Estado Social ou à democracia concreta.

\subsection{A igualdade e critérios constitucionais de igualação e desigualação na igualdade material}

Há a necessidade de se separarem e estabelecerem critérios que permitam agrupar os seres em iguais e desiguais, traçando linhas mestras da igualdade material e cristalizando a escala de valores constitucionalmente adotados no Brasil.

Tratando deste aspecto pode-se observar:

O que a garantia constitucional quer impedir é a discriminação que nasce pela intenção de discriminar. A desigualdade inadmitida é aquela em que se desiguala por razão motivada e apoiada na finalidade de desigualar. Por isso a igualdade pretendida, no texto constitucional, é relativa ou formal. Em outros termos, aquela em que se inadmite a ação desigualitária que não se apóie em princípios aceitos pelo ordenamento jurídico-constitucional ou que se embase na finalidade exclusiva de discriminar ${ }^{18}$. 
$\mathrm{O}$ art. $5^{\circ}$ da Constituição Federal, que enuncia a igualdade de todos perante a lei, sem distinção de qualquer natureza, não se esgota em si mesmo, complementando-se em diversos incisos deste mesmo artigo e também em outros, como independência de poderes, legalidade, entre tantos outros. A lei não deve ser fonte de privilégios ou perseguições, mas instrumento regulador da vida social, que necessita tratar eqüitativamente todos os cidadãos. Este é, pois, o conteúdo político-ideológico absorvido pelo princípio da isonomia e juridicizado pelos textos constitucionais em geral.

Celso Antonio Bandeira de Mello preleciona:

O princípio da igualdade interdita tratamento desuniforme às pessoas. Sem embargo, consoante se observou, o princípio da lei, sua função perspícua, reside exata e precisamente em dispensar tratamentos desiguais. Isto é, as normas legais nada mais fazem que discriminar situações, à moda que as pessoas compreendidas em umas ou em outras vêm a ser colhidas por regimes diferentes. Donde a algumas são deferidos determinados direitos e obrigações que não assistem a outras, por abrigadas em diversas categorias reguladas por diferente plexo de obrigaçōes e direitos $^{19}$.

A correta aplicação da lei no constitucionalismo moderno deve ser realizada no sentido material, na acepção de correta aplicação da norma validada, à vista dos requisitos formais e substanciais da Constituição Federal.

Pessoas diferem-se relativamente, possuindo cada uma sua individualidade, no que tange às características personalíssimas, porém, nos termos do art. $5^{\circ}$, estas diferenças não ensejam tratamento jurídico desigual, isto é, são diferenças absolutamente irrelevantes, vedando-se sua consideração a fim de se atribuir aos cidadãos regime jurídico diverso. No sentido negativo, a Constituição Federal veda quaisquer preconceitos de origem, raça, sexo, cor, idade e outros que não têm relevância jurídica para impor um discrímen na elaboração legislativa.

Em qualquer situação, a lei erige algo em elemento diferencial, apanhando nas diversas situações qualificadas algum ou alguns pontos de diferença a que atribuiu relevo para fins de discriminar situações, impondo a cada qual efeitos jurídicos correlatos e, de conseguinte, desuniformes entre si.

Celso Antonio Bandeira de Mello propõe regras que ensejam avaliar aquelas distinções estabelecidas na norma, decidir sobre a constitucionalidade ou 
inconstitucionalidade das desigualdades eventualmente consideradas pelo legislador.

Há ofensa ao preconceito constitucional da isonomia quando: 1 - a norma singulariza atual e definitivamente um destinatário determinado, ao invés de abranger uma categoria de pessoas, ou uma pessoa futura e indeterminada;

2 - a norma adota como critério discriminador, para fins de diferenciação de regimes, elemento não residente nos fatos, situações ou pessoas por tal modo desequipadas. É o que ocorre quando retende tomar o fato "tempo" que não descarna no objeto como critério diferencial;

3 - a norma atribui tratamentos jurídicos desiguais diferentes em atenção a fator de discrímen dotado que, entretanto não guarda relação de pertinência lógica com a disparidade de regimes outorgados;

4 - a norma supõe relação de pertinência lógica existente em abstrato, mas o discrímen estabelecido conduz a efeitos contrapostos ou de qualquer modo dissonantes dos interesses prestigiados constitucionalmente;

5 - a interpretação da norma extrai dela distinções, discrímen, desequiparações que não foram professadamente assumidas por ela de modo claro, ainda que por via implícita ${ }^{20}$.

\subsection{0 dever de distinguir}

A partir de um caso concreto, no Brasil, via norma constitucional cogente, a progressividade é apresentada como instrumento tributário para a construção de uma sociedade mais livre, mais justa e solidária, utilizada no imposto de renda das pessoas físicas ou naturais.

A relação entre preços e salários e a participação destes na renda nacional são importantes fatores que diretamente intervêm no grau de justiça social.

O princípio da igualdade é invocado, então, para justificar as desigualdades de tratamento dos economicamente mais fracos, com o fim de reduzir as grandes disparidades e favorecer a igualação das condições concretas.

Este enfoque material em momento algum contrapõe-se à concepção unânime da igualdade formal. Os economicamente mais debilitados são classificados como seres de uma outra categoria essencial, que não podem ser tratados da mesma maneira e modo que os economicamente mais fortes.

Como regra geral, a lei precisa basear-se em princípios justos, e se esse princípio não existe, dá-se o arbítrio, há ausência de princípios jurídicos, há 
vontade qualquer. O princípio do justo fornece os critérios para medir o que é digno de pena, de prêmio, de ajuda social, de subvenção social ou de imposto.

Confirmando este raciocínio, na doutrina pátria encontramos referendo em Celso A. Bandeira de Mello, que ensina que a norma sempre deve atingir toda uma categoria de pessoas que se encontrem na mesma situação, sem colher só a uma determinada; deve haver relação de pertinência lógica entre o tratamento discriminatório e o objetivo legal perseguido; a discriminação deve buscar diferenças reais de elementos residentes nos próprios fatos e não estranhos ao objeto, como ocorreria se escolhesse o fator tempo.

\section{Conclusão}

Estamos, pois, diante de um quadro que resumidamente podemos apontar: a- uma proposta de reserva de $50 \%$ de vagas nas universidade públicas a alunos oriundos das escolas públicas;

b- a educação é um serviço público de natureza essencial e que deve observar princípios constitucionais como garantia de qualidade, eficiência que permitam acesso a níveis superiores de educação;

c- observa-se no discurso oficial a busca da melhoria da qualidade de ensino e da eficiência na prestação do serviço público de educação, a partir do reconhecimento da inadequação e da baixa qualidade comprovada e confessa;

d- a baixa qualidade do ensino público é fator básico de discriminação e exclusão do aluno oriundo da rede pública de ensino, no que se refere a busca por vagas dos cursos mais concorridos e pretendidos das universidades públicas;

e- a busca do tratamento isonômico passa, necessariamente, por considerarem-se os fatores que provocam as desigualdades, notadamente, quando promovidas por aspectos alheios às possibilidade do homem, que os desigualam de forma inapelável.

Estes aspectos exáustivamente observados nos levam a concluir que uma íniciativa como esta, a de reservar vagas na universidade pública para alunos egressos da escola pública, não tem o condão discriminatório de afastar o aluno, e sim de trazê-lo, integrá-lo, constituindo na chamada "discriminação a favor". Esta ocorre quando a sociedade reconhece a existência de desigualdades que são reforçadas pelo sistema jurídico.

Aceitável é dizer-se que tem aspecto paliativo, onde a qualidade do ensino brasileiro por certo será buscada permanentemente, principalmente nos Ensinos Fundamental e Médio, principalmente com o retorno da classe média para a escola pública e sua conseqüente participação e cobrança de sua melhoria e eficiência. 


\section{Bibliografia}

BALEEIRO, Aliomar. Limitações constitucionais ao poder de tributar. 7. ed. Rio de Janeiro: Forense, 1977.

BONAVIDES, Paulo. Curso de direito constitucional. 7. ed. São Paulo: Malheiros, 1998.

CRETELA JUNIOR, José. Dicionário de direito administrativo. 4. ed.Rio de Janeiro: Forense, 1998.

DI PIETRO, Maria Sylvia Zanella. Direito administrativo. 11. ed. São Paulo: Atlas, 2000.

MEIRELLES, Hely Lopes. Direito administrativo brasileiro. 25. ed. São Paulo: Malheiros, 2000.

MELLO, Celso Antonio Bandeira de. Conteúdo jurídico do princípio da igualdade. 3. ed. São Paulo: Malheiros, 1997.

. Curso de direito administrativo. 11. ed. São Paulo: Malheiros, 1999.

MOREIRA NETO, Diogo Figueiredo. Curso de direito administrativo. 11. ed. Rio de Janeiro: Forense, 1996.

NASCIMENTO, Tupinambá Miguel Castro do. Comentários a Constituição Federal. Porto Alegre: Livraria do Advogado, 1997.

REVISTA EDUCAÇÃO, Editora Segmento, n. 231, maio 2003.

SILVA, José Afonso da. Aplicabilidade das normas constitucionais. 3. ed. São Paulo:

Malheiros, 1999.

SUNDFELD, Carlos Ari. Fundamentos de direito público. 3. ed. São Paulo:

Malheiros, 1997. 